\title{
Morphological features of different accessions of Chenopodium quinoa
}

\author{
Muhammad Farooq Azhar ${ }^{1}$, Shahid Aziz ${ }^{2}$, Abida Aziz ${ }^{3}$, Muhammad \\ Javaid $^{2}$, Hafiz Muhammad Aatif ${ }^{4}$, Allah Wasaya ${ }^{4}$, Tauqeer Ahmad \\ Yasir" and Abdul Wahid Baloch ${ }^{5}$ \\ 1. Department of Forestry and Range Management, Bahauddin Zakariya University, Multan-Pakistan \\ 2. Department of Botany, The University of Lahore, Sargodha Campus-Pakistan \\ 3. Department of Botany, The Women University, Multan-Pakistan \\ 4. College of Agriculture Bahauddin Zakariya University, Bahadur Sub-Campus Layyah-Pakistan \\ 5. Department of Plant Breeding \& Genetics, Sindh Agriculture University, Tandojam-Pakistan \\ *Corresponding author's email: tayasir@yahoo.com \\ Citation \\ Muhammad Farooq Azhar, Shahid Aziz, Abida Aziz, Muhammad Javaid, Hafiz Muhammad Aatif, Allah \\ Wasaya, Tauqeer Ahmad Yasir and Abdul Wahid Baloch. Morphological features of different accessions of \\ Chenopodium quinoa. Pure and Applied Biology. Vol. 7, Issue 1, pp374-383. \\ http://dx.doi.org/10.19045/bspab.2018.70046
}

\begin{tabular}{llll}
\hline \hline Received: 03/11/2017 & Revised: 07/02/2018 & Accepted: 19/02/2018 & Online First: 08/03/2018 \\
\hline
\end{tabular}

\section{Abstract}

Quinoa is an annual herbaceous plant which belongs to family Amaranthaceae. It has a variety of flower colors like green, red and purple. Leaf colour ranges from green to red depending upon the nature of pigments present. Recent research work was focused on detailed study of morphological and anatomical features of four different accessions of Chenopodium quinoa grown in semi-arid climate of Faisalabad, Pakistan. Important morphological parameters (growth habit, length and weight of roots, length and weight of stem, width and weight of leaf, weight and structure of panicle and seed) were studied. P19 accession was found to have maximum height $(190.7 \mathrm{~cm})$ and higher biomass fresh weight $(281.7$ grams) than other accession. Accession P93has maximum root length of $25.3 \mathrm{~cm}$ while that of P19has minimum root length of $22.6 \mathrm{~cm}$. However over all there is no much significant difference in root lengths of all accessions.

Keywords: Accessions; Morphological features; Nutritional crop; Panicle length; Quinoa; Root parameters

\section{Introduction}

Chenopodium quinoa belongs to the family Amaranthaceae and resembles to Spinacia oleracea and Beta vulgaris [1]. Chenopodium quinoa is allelotetraploid $(2 n=4 x=36)$ plant and its disomic inheritance was observed with respect to the majority of the traits $[2,3]$. It was reported that stem of the plants are succulent and jointed. Actinomorphic and small flowers are produced on these plants having 3-5 sepals surrounding the fruit which may be fused or free basally. The plants of this family have berry shaped capsules, or nutlets fruits having strongly curved seeds inside [4]. Quinoa also termed as the poor's people crop belonging to the Andean region (South America) and major staple food for natives [5, 6]. Quinoa has slightly bitter taste due to anti nutritional saponin [7].

The malnutrition problem in all over the world can be addressed by increasing cultivation of alternative crops like quinoa. It has all necessary amino acids necessary for nutrition. Presence of lysine made it nutritionally very important. Its leaves and seeds are already being consumed as food source in South America, Asia, and Europe. The bread and the cakes are prepared from 
the flour of quinoa seeds [8]. Quinoa seeds as a food are consumed by man and added in animal feeds at smaller level since many years [9]. But still it is not listed in main staple food. Seeds of $C$. quinoa have been reported to comprise of carbohydrates, lipids and proteins which makes it the excellent food source $[10,11]$. Further, balancing amino acids composition and presence of $16 \%$ protein contents by weight in seeds is excellently according to the nutritional needs of the human beings $[6$, 12, 13]. It has abilities to tolerate the extreme conditions of the environment [14]. The people of the developing countries are taking great interest in quinoa [15].

Quinoa shows genetic diversity with respect to its flowers, colour, seed shape, protein, calcium oxalates and saponin contents in leaves, which appeal breeders or farmers to cultivate it in all ecological conditions [16]. It can be adopted successfully in diverse environments starting from the sea level up to $4000 \mathrm{~m}$ above and from $40^{\circ}$ South to $2^{\circ}$ North of latitude. The surprising adoptability of the quinoa is that at sea level it is less sensitive to the long term high temperature. This shows its extreme adaptability to the environment [17].

Very less research work was done to explore its genetics, molecular and morphological characteristics in subtropics where majority of developing countries exist. In our society like other developing nations, the food and nutritional conditions do not meet the world health standards. Further very limited options are available as staple food. New food alternatives are required to be explored like this plant. For this purposes identification, the morphology and anatomy of a plant along with ecological behavior is needed to be considered for introducing new alternatives. In this study, all these parameters of this plant along with growth were studied in Faisalabad region of Pakistan. This made it possible to differentiate $C$. quinoa from other plants and also provided the features for its own uniqueness among different accessions and the species of a genus in a family. Further, it will increase our staple food choices.

\section{Materials and methods \\ Plant samples collection}

Seeds of four promising quinoa accessions i.e. P93 labeled as $A_{1}$ and Ames 30 as $A_{2}$ (Figure 1), Ames 37 as $\mathrm{A}_{3}$ and P19 as $\mathrm{A}_{4}$ (Figure 2) were sown on ridges in experimental area of Crop Physiology department during early December, 2015 at University of Agriculture, Faisalabad, Pakistan. The climate of Faisalabad is a semi-arid climate as very hot and humid in summers while cool winters with less or no rainfall. The seed at the rate of $18 \mathrm{~kg} \mathrm{ha}^{-1}$ was sown in rows of $75 \mathrm{~cm}$ apart from each other with plant to plant distance of $15 \mathrm{~cm}$ by hand drill. Diammonium phosphate (DAP) fertilizers @ $65 \mathrm{~kg} \mathrm{ha}^{-1}$ was applied as a source of nitrogen and phosphorus. Whole phosphorus and $1 / 2$ of nitrogen quantities were applied as initial doses and the rest of them were applied at the stage of flowering. The samples of plants were collected from time of emergence to the final harvest and observed for morphological and anatomical features. The samples were observed with naked eye as well as with the microscope and ocular micrometer. The accessions of Chenopodium quinoa were harvested at the time of maturity on 15th to 28th of April, 2016, correspondingly.

\section{Morphological data}

Morphological data concerning the time to emergence, formation of true leaves, bud formation, panicle size and emergence, flowering, and maturity were obtained. Three plants of each accession were taken to measure the crop growth and flowering till seed formation and then average of three plants is used in results. Before inflorescence, the data of vegetative parts i.e. root, stem, leaves was recorded. At the flowering stage the inflorescence was recorded. After harvesting, data relating seeds was taken. The whole data was recorded and tabulated. 

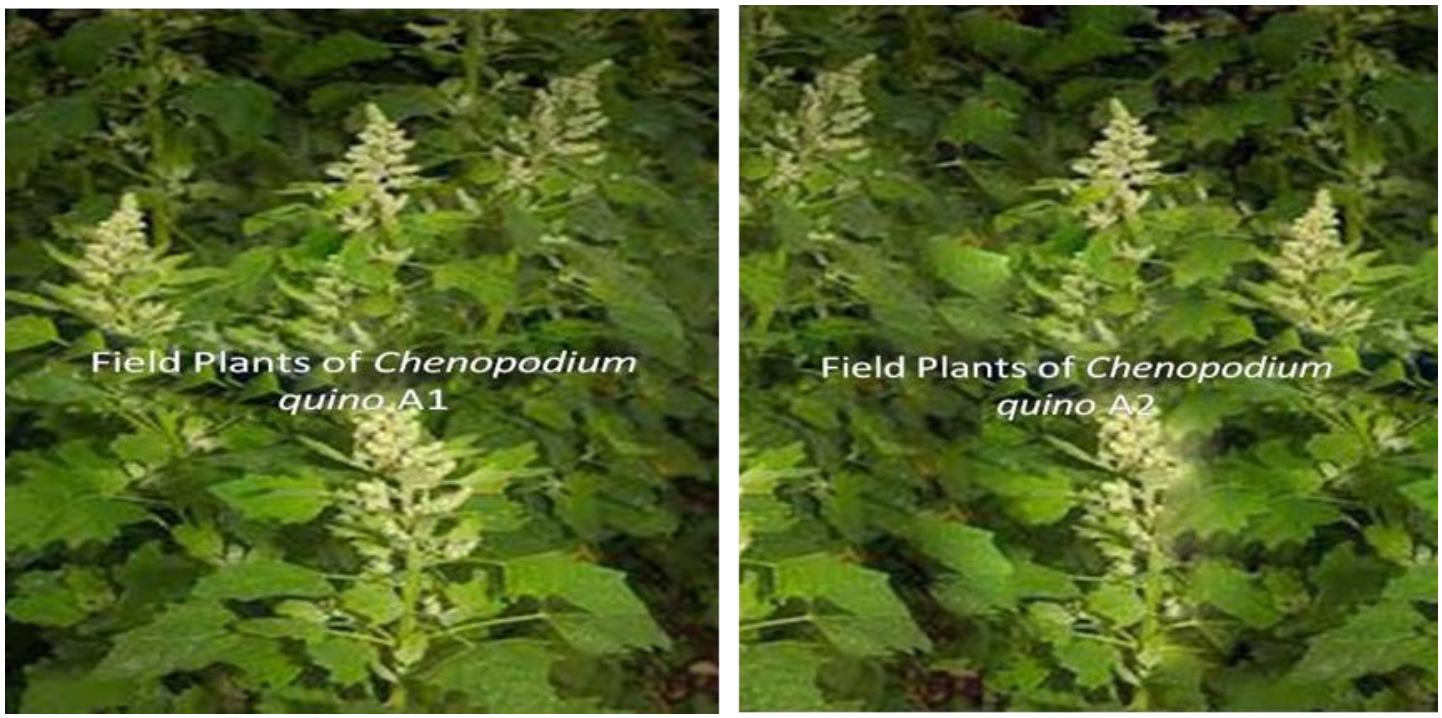

Figure 1. Plants of Chenopodium quinoa Accessions P93 and Ames 30
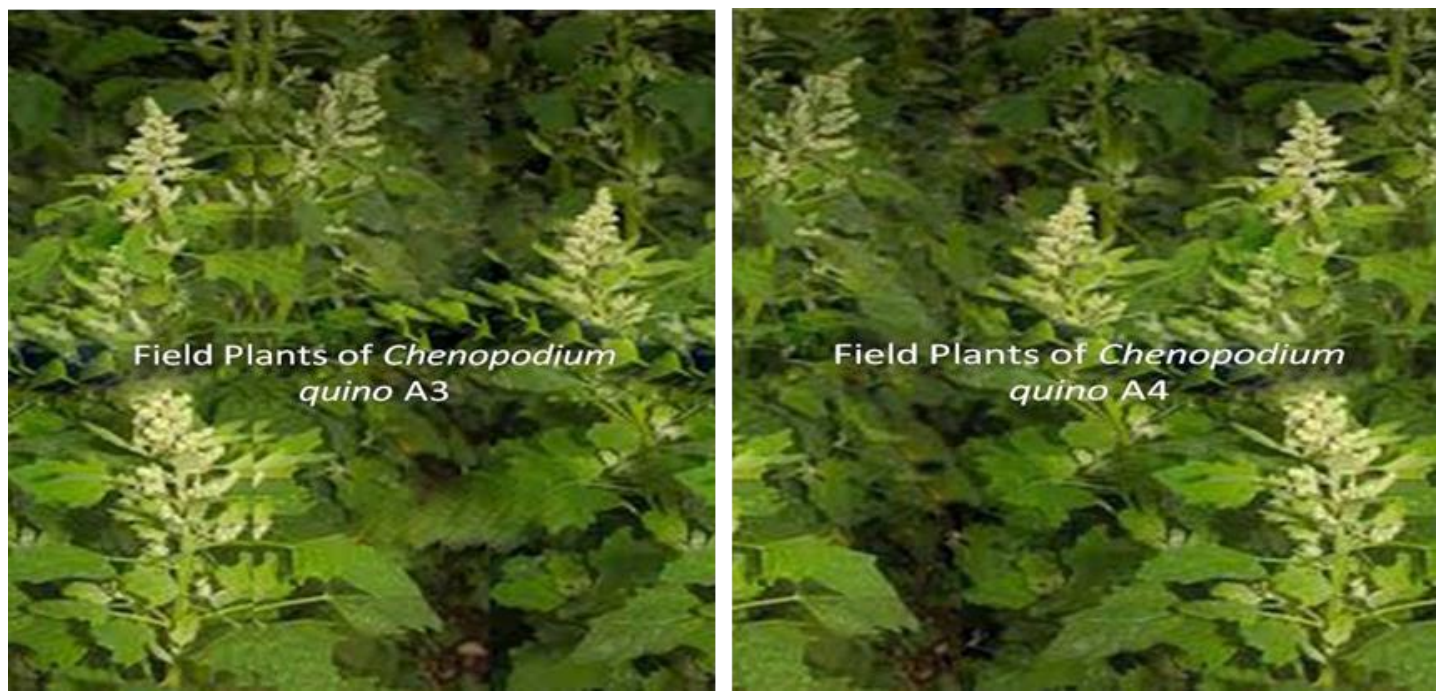

Figure 2. Plants of Chenopodium quinoa accessions Ames 37 and P19

\section{Plant height and weight}

Plant heights $(\mathrm{cm})$ was measured with the help of a simple measuring tape in centimeters and their average values were used. The weight of the Chenopodium quinoa was calculated by using the analytical weighing balance.

\section{Root parameters}

The root parameters were calculated to study the root morphology. Fresh and dry weight of root, stem and leaves were measured. For the growth parameter it was calculated including weight of root, stem, and leaf. Length of the root was measured from the first emerging node of the plant to last part of the root. Width of the root was measured with the help of digital vernier caliper. The width of the root was calculated at three different locations like top most region, bottom most and the middle region. Mean of these three values was calculated to get the root width. Density of lateral roots was known through counting their numbers. Weight of the root was calculated through general lab weighing machine with ability to measure up to 1 gram.

\section{Stem parameters}

Stem parameters were calculated like stem height through ruler with the scale of centimeters. It was measured from the first emerging node of the plant till the acquiring maximum height. Weight of the stem was calculated by using weighing machine with at least 1 gram. Number of branches, nodes, leaves on the stem was noted through 
simple counting on the stem. The length of internodes was calculated using the scale. Stem diameter was calculated at three different locations with the help of digital Verneir Caliper. Their mean was calculated to get the final stem diameter of the plant. Qualitative traits were observed with naked eye observation.

\section{Leaf parameters}

Leaf parameters were measured with the help of simple tools. Leaf petiole and leaf length was measured in centimeters with ruler. Weight of the leaf was measured with the help of digital balance. No. of leaves with equal physique were weighed and their mean was calculated to get the weight of a single leaf.

\section{Inflorescence}

Inflorescence of the Chenopodium quinoa was keenly observed. Panicle length was measured in centimeters with the help of a ruler.

Seeds

Seeds of the C. Quinoa accessions were of golden color with a dark strip. The diameter of the seed was calculated by using screw gauge. One gram seeds of each accession were separated and number of seeds per gram was counted.

The grains were observed in the panicle by opening perigonium. This is a characteristic of physiological maturity.

\section{Results and discussion}

From the results (Figure $3 \& 4$ ) it is clear that the average height of P19 accession was found maximum $(190.7 \mathrm{~cm})$ while that was minimum $(180.2 \mathrm{~cm})$ in $\mathrm{P} 93$ accession. The average height of AMES30 and AMES37 accession remained in between the heights of P93 and AMES30 accessions. P19 plant had maximum height which was due to the presence of actively dividing meristematic cells. Maximum average fresh weight (281.7grams) was observed in P19 while minimum (255.3 grams) was in P93. As the root system of P19 had much higher weight due to the presence of more height and width as compared to others, so in P19 plants root system had maximum fresh weight as compared to other three accessions. The decrease in dry weight depends upon the removal of the water content. Whenever these accessions of quinoa were weighed in dry conditions, it showed that AMES30 had maximum dry weight while that of P93 had minimum dry weight. AMES37 had dry weight lesser than Ames30, similarly P19 had lesser than AMES37 respectively. The growth of the $C$. quinoa was more during the period of October to April and maximum biomass was obtained at that time period. The smaller day length contributes to the increased absorption of water and salts from the soil and resulted in increased nutrient absorption. This led to production of more photo-assimilates and enhanced other metabolic activities like protein synthesis, respiration, starch and other macromolecule formations [18]. Due to increased metabolic activity, the height of plant, number of branches, leaves and roots also increases. All this happens according to the expression of genes present in the cells of the plants. It was observed that P93, Ames30, Ames37 and P19 gradually increase their height. Increase in the height and the weight of the plant is the result of increased cell division, cell differentiation and enlargement. All these factors increased the cellular mass and resulted in the increased growth, development and biomass of plant. The length of the growth period was positively correlated to the growth, plant height and yield. P19 accession grew taller and was superior in the grain yield. The varieties with smaller plant height showed less growth and lesser growth parameters [18]. 


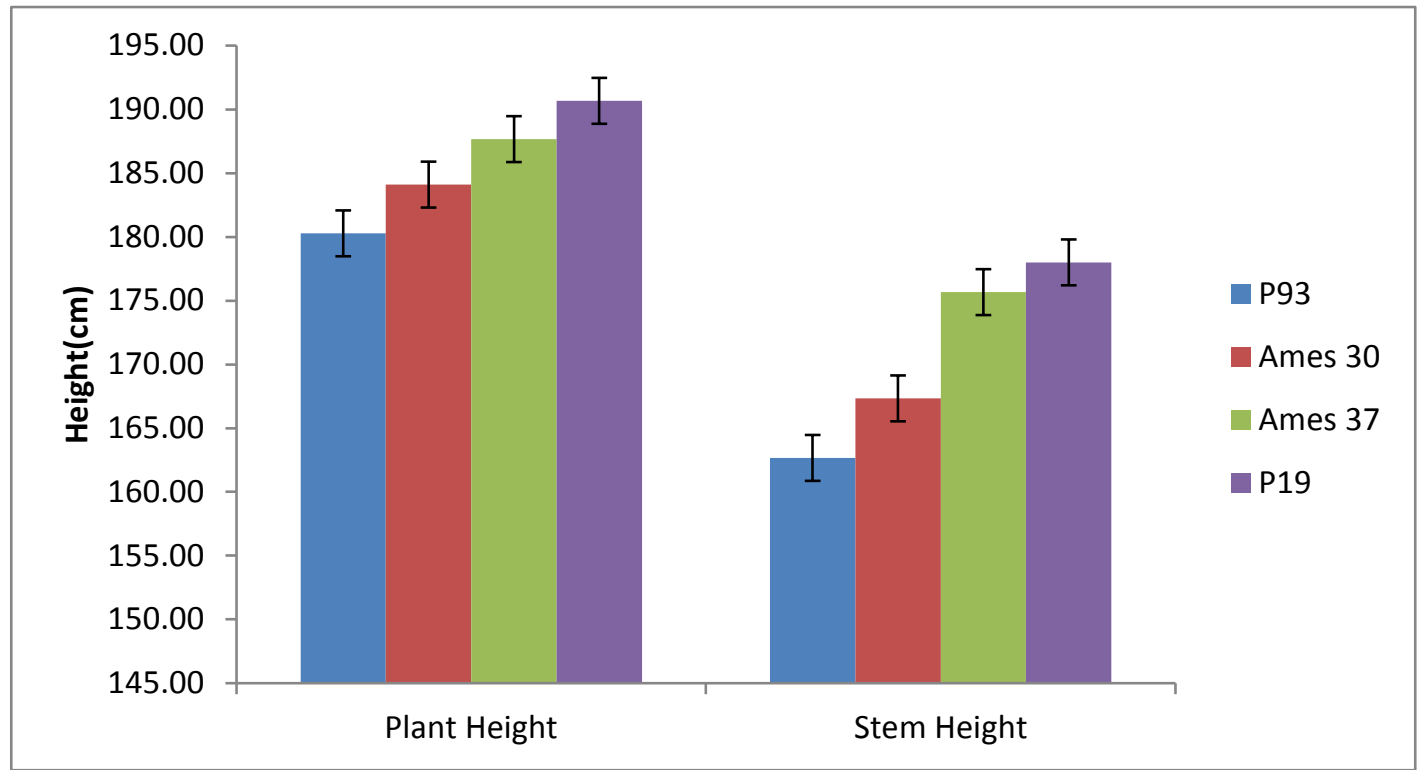

Figure 3. Chenopodium quinoa Plant Height

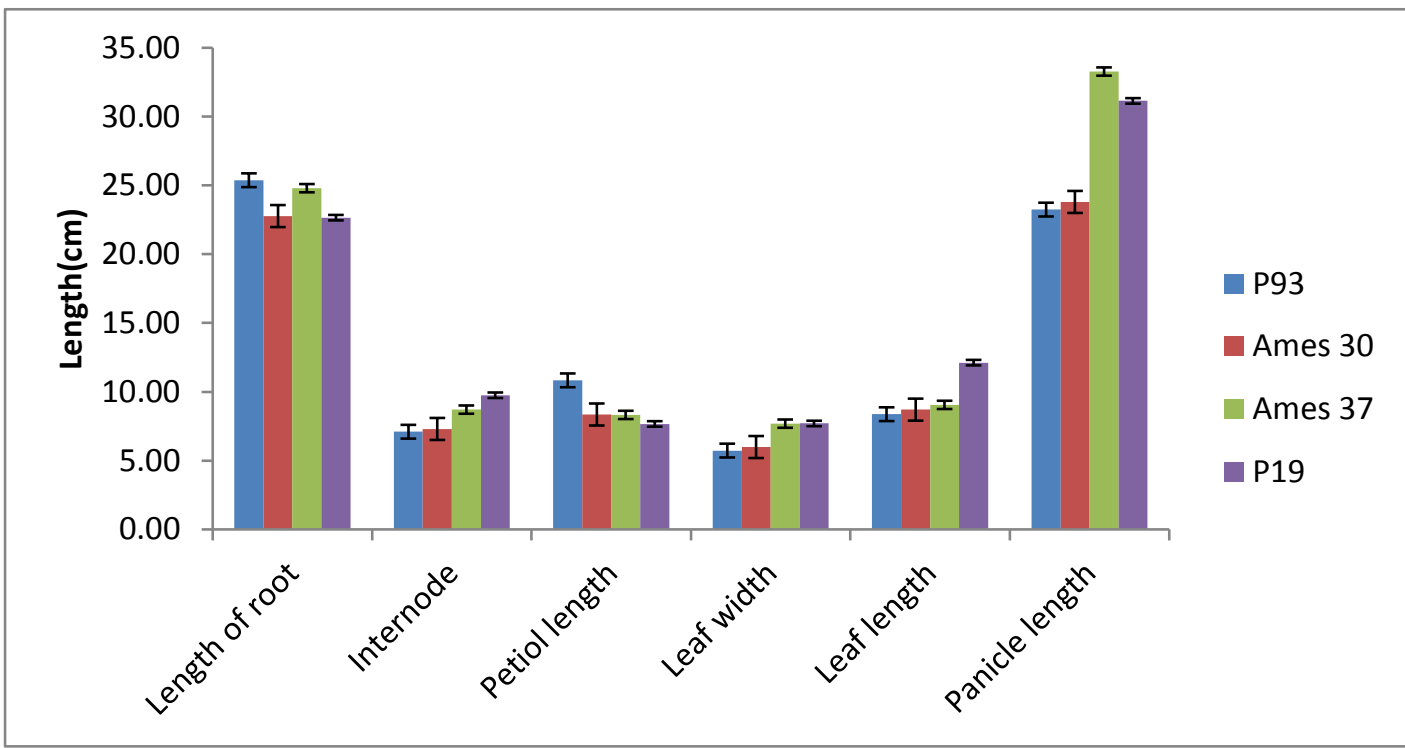

Figure 4. Chenopodium quinoa root length, internodes, petiol length, leaf width and hieght

\section{Panicle length}

Number of lateral roots were calculated maximum in P19 accession and minimum in P93 accession. While that of AMES30 and AMES37 were intermediate. P93 accession showed maximum root length while that of AMES30 and P19 had minimum which show the less growth of the root respectively. Accession P93 showed maximum root length $(25.3 \mathrm{~cm})$ while that of P19 had minimum root length $(22.6 \mathrm{~cm})$. However, there was no significant difference in root lengths of all accessions (Figure $5 \& 6$ ). As for as the width of the root were concerned, P19 had maximum i.e., $1.61 \mathrm{~cm}$ root width while $\mathrm{P} 93$ had minimum $1.32 \mathrm{~cm}$ root width. There is no significant difference in root widths of other accessions. P19 had maximum fresh weight (37.33 grams) of root and P93 showed minimum fresh weight of root (22 grams). Similar trend was observed for dry weight of the root. 


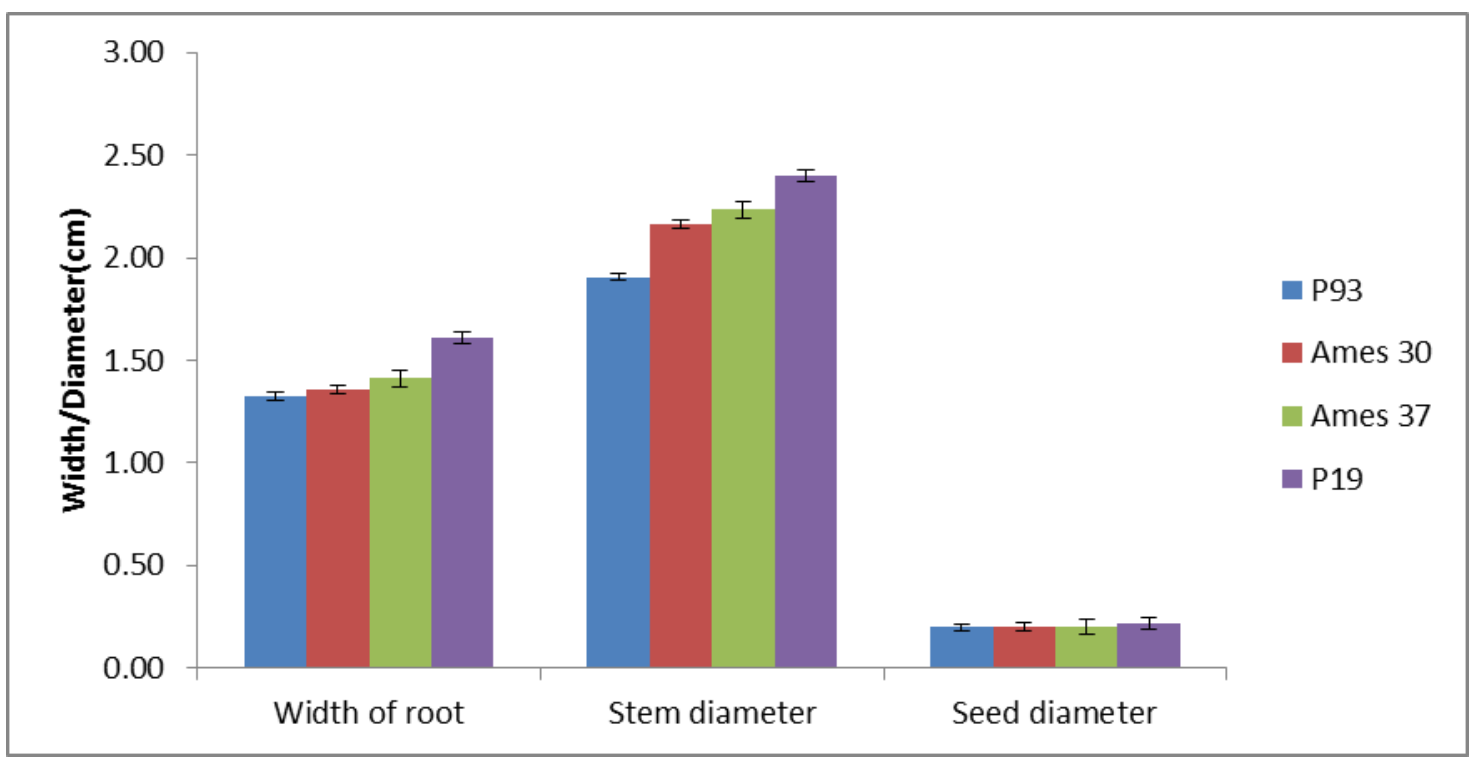

Figure 5. C. quinoa width of root, stem diameter and Seed diameter

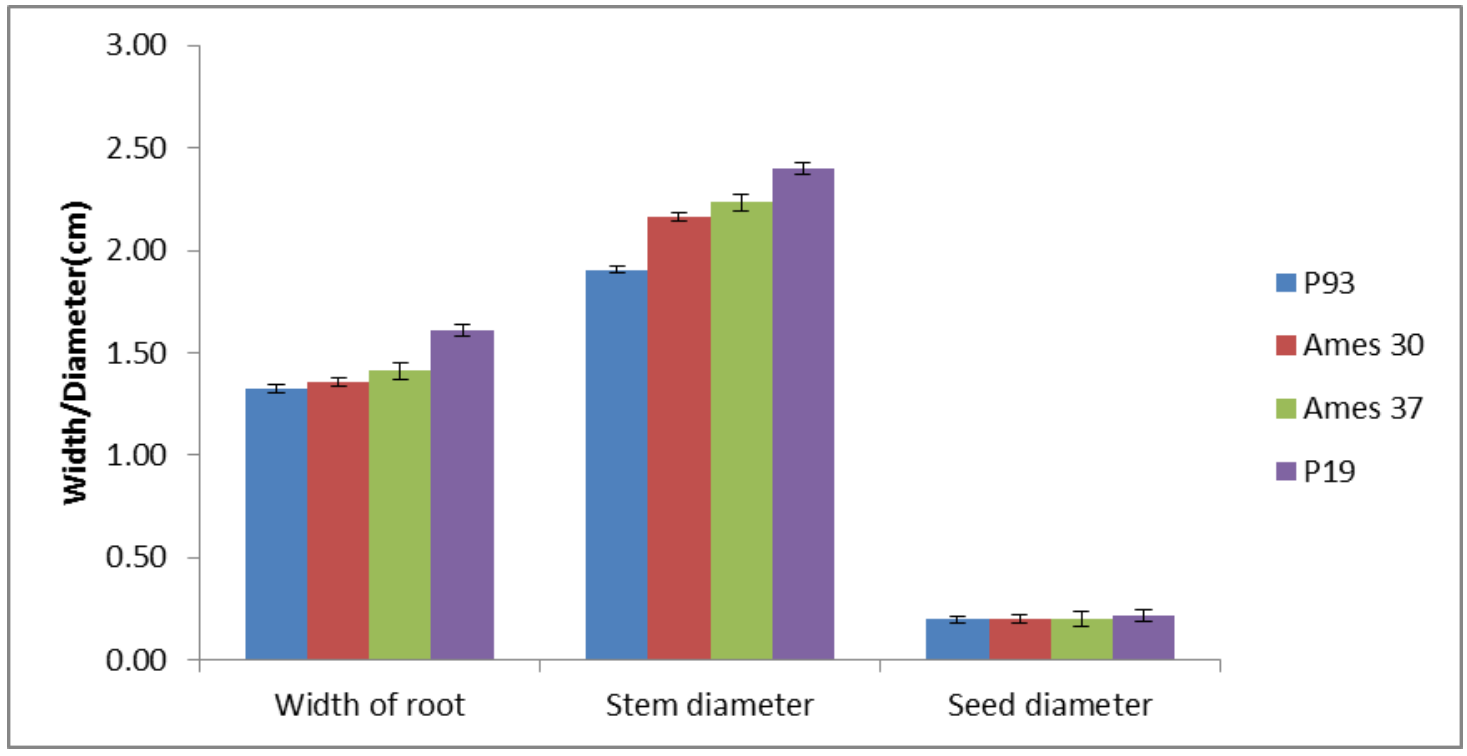

Figure 6. C. quinoa width of root, stem diameter and seed diameter

AMES30 accession had maximum number of branches on main stem as compared to other three accessions. The accession AMES37 had minimum number of branches on main stem. P19 accession had maximum stem diameter $(2.4 \mathrm{~cm})$ whereas P93 had minimum stem diameter $(1.9 \mathrm{~cm})$ while AMES30 and AMES37 showed stem diameter $2.16 \mathrm{~cm}$ and $2.23 \mathrm{~cm}$ respectively. The stem diameter of P19 accession was $0.5 \mathrm{~cm}$ more than that of P93. The increase of stem diameter is presenting the more secondary growth. The vascular cambium is more developed. As for as no. of nodes were concerned the P19 accession had maximum no. of nodes (17 nodes), whereas P93 accession had minimum number of nodes (13 nodes). Maximum internodal distance $(9.75 \mathrm{~cm})$ was observed in P19, while minimum internodal distance (7.1 $\mathrm{cm})$ was in P93. Non-significant difference were observed in AMES30 $(7.3 \mathrm{~cm})$ and P93accession $(7.1 \mathrm{~cm})$. Maximum fresh weight of main stem were observed in P19 (251grams) of the fresh weight of main stem and is maximum fresh weight because 
the stem diameter of this accession is much more than other three accessions whereas it was minimum for P93accession (245.6 grams). The AMES30 and AMES37 showed intermediate results respectively. The dry weight of all of these accessions was also showing the same pattern of study (Figure $7 \& 8$ ).

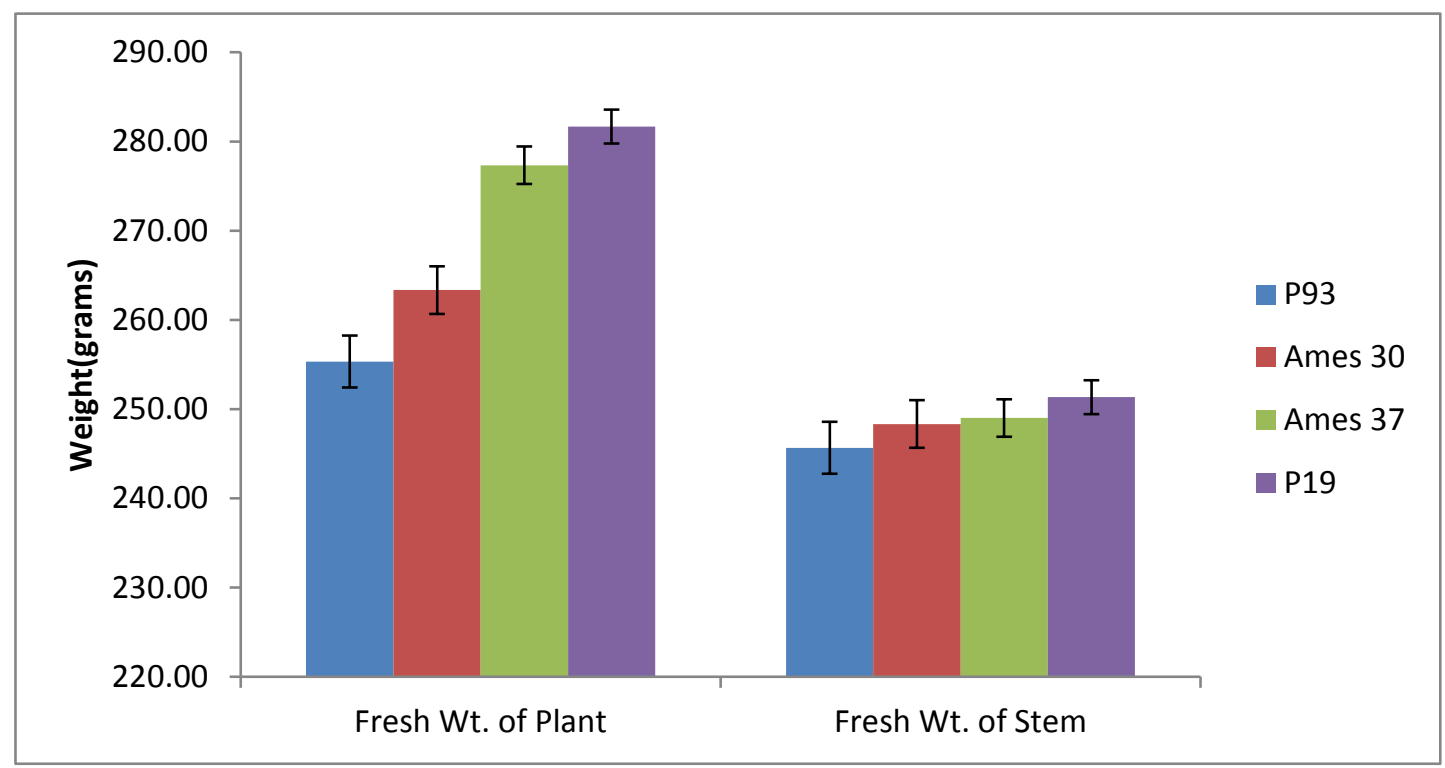

Figure 7 C. quinoa fresh weight of plant and fresh weight of main stem

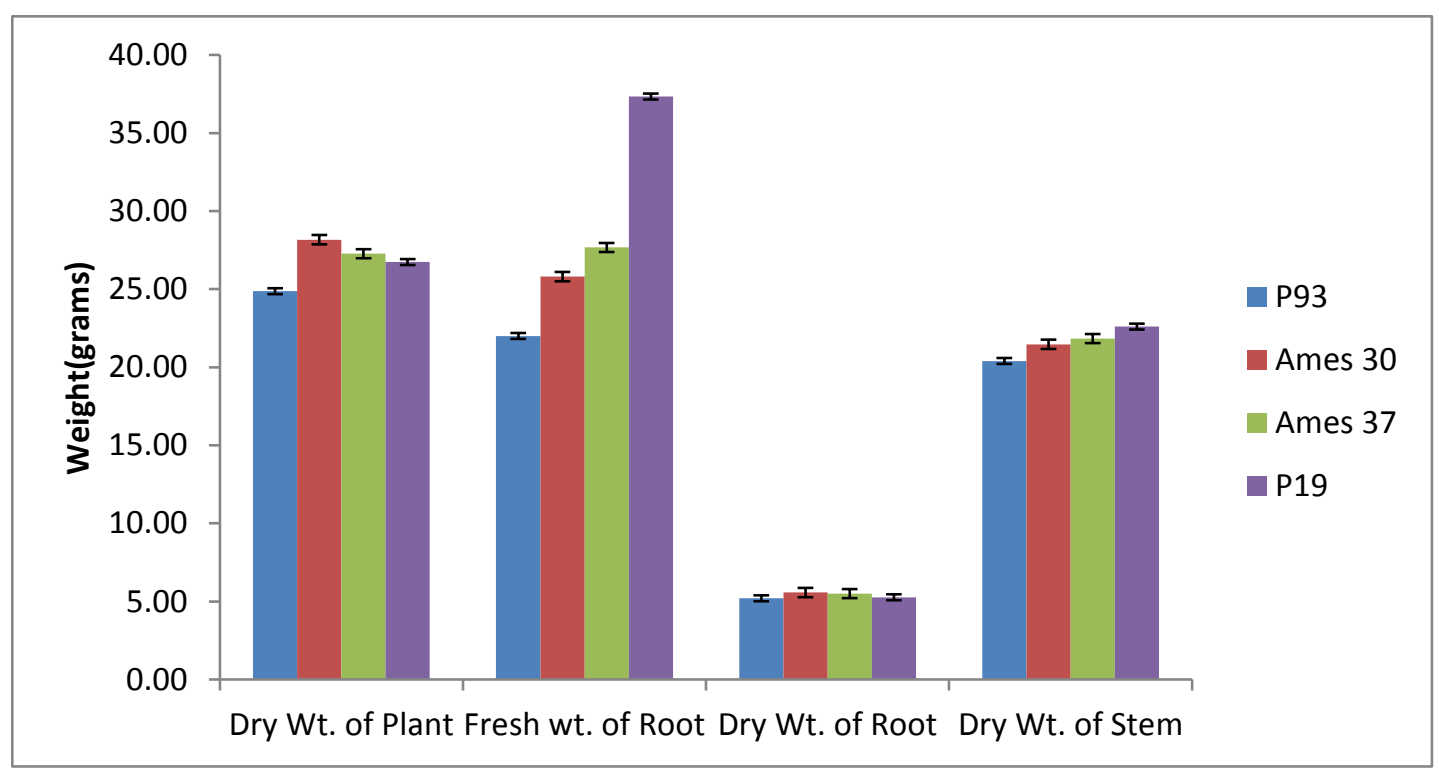

Figure 8. Dry weight of plant, fresh weight of root, dry weight of root and dry weight of stem

The data revealed that No. of leaves on main stem in accession P19 was maximum as compared to all other accessions. The number of leaves on main stem is minimum on P93 accession. The increase in number of leaves is the sign of more and more harvesting of the sunlight. Therefore the growth of the plant will increase. This is the machinery converting Sunlight energy into biochemical energy.

As for as petiole length was concerned, it was maximum in P93 while minimum in P19 accession. Non-significant difference was observed between of AMES30 and AMES37 accession. Similar trend for length and width was observed P19 showed 
maximum results. Accession P93 had least leaf width. The width of the leaf blade of other two accessions is present between these accessions. Accession AMES37 has maximum fresh leaf weight as compared to other three accessions. This may be due to larger leaf area of accession AMES37, as compared to other accessions (Figurer 9).

Seed diameter of AMES37 and P19 were almost equal however seed diameter of AMES30 was less than other three accessions. Like Seed diameter, fresh weight of AMES37 and P19 were almost equal however fresh weight of AMES30 was less than other three accessions.

The inflorescence of C.quinoais racemose panicle. The branches of the panicle are also present. The panicle is soft not a compact one. Panicle length of accession AMES37 is greater than other three accessions. Accession P93and AMES30 has almost equal panicle length. Panicle length of accession AMES37 is greater than other three accessions. Accession P93and AMES30 has almost equal panicle length.As a consequence, at the apices of the main stem panicles were produced in which seeds were developed with scaling and seeds were matured. If there is uniform panicle ripening, it provides additional benefit to reduce the seed loss. Ultimately, it causes the removal of the stem easy. It results the lesser damage to the seed. Humidity also affects the seed harvesting. For good harvesting there should be the lesser and lesser humidity. The small sized seeds are endangered if the proper harvesting of the crop does not take place [19]. Variation in morphological parameters of different accession of this plant in various temperate, tropical to subtropical regions was also discussed by various scientists [20-23]. Increase in seed yield, size with the increase of nitrogen fertilizer was also observed by [24].

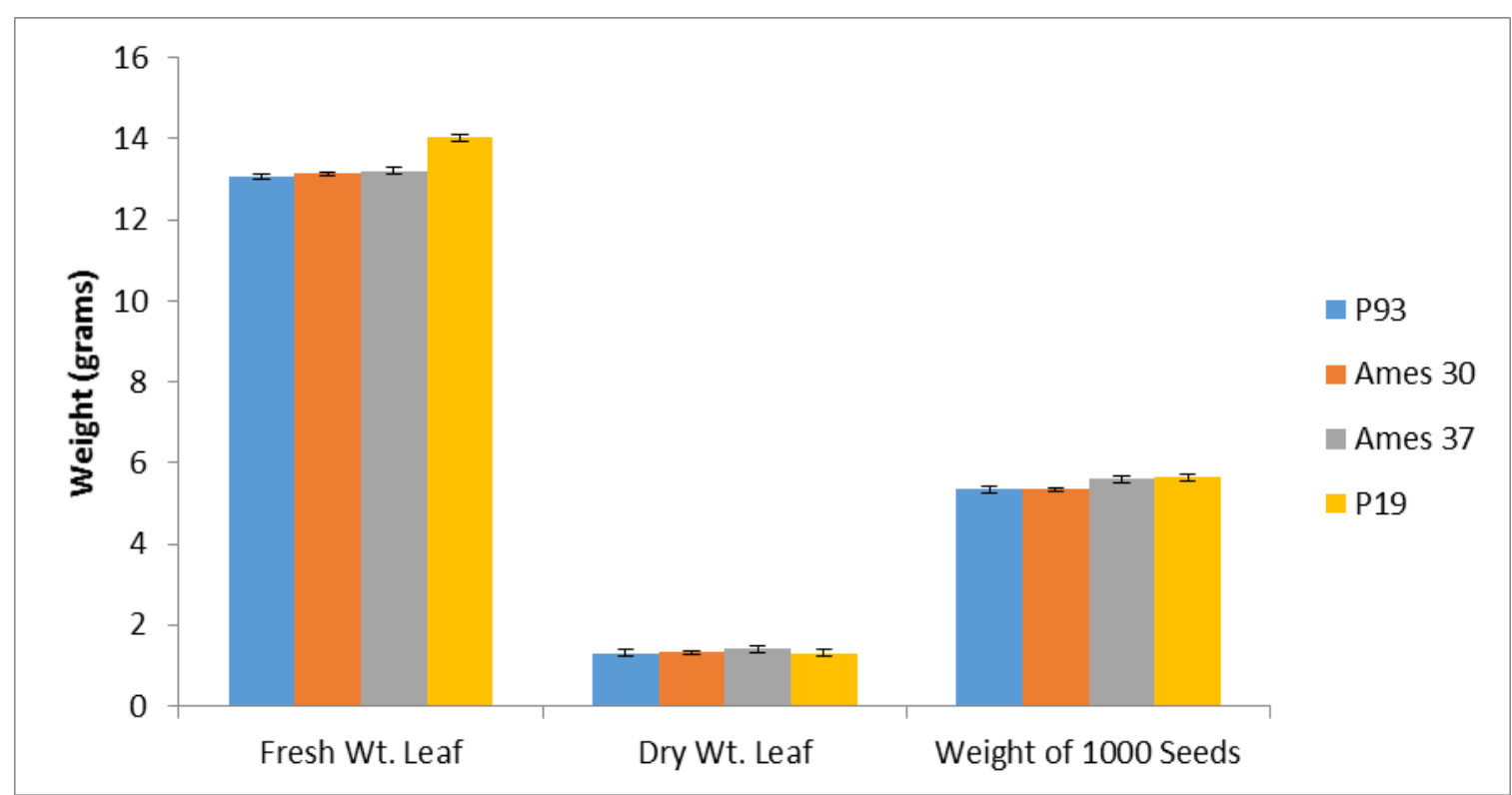

Figure 9. Chenopodium quinoa Fresh weight of leaf, Dry Weight of leaf and Weight of

\section{0 seeds}

\section{Conclusion}

The results showed that the quinoa took 70.78-101.55 days to flowering and 109.33163.33 days to maturity. The inflorescence is racemose panicle. All accessions showed good growth performance in subtropical and semiarid climatic conditions of Pakistan. The seed yield is also encouraging. It could be suggested that all tested quinoa accessions may serve as an alternative winter crop for dry plains because of its tremendous potential. These accessions can successfully be cultivated in other parts of the country with semi-arid climatic conditions. Its growth behavior is encouraging for farmers to introduce it in 
conventional cropping systems. By further experimenting and reducing its maturing time will increase the prospects for including quinoa in rotation or double cropping systems. Its cultivation on large scale will be helpful in increasing farmer level income and improving the diet of low income populations. The high quality protein may be a key factor for its cultivation and introducing into the agroindustry. It could be a good protein source for human diet and be a part of animal and chicken feed.

\section{Author's contributions}

Conceived and designed the experiments: MF Azhar \& TA Yasir, Performed the experiments: S Aziz, A Aziz \& M Javaid, Analyzed the data: AW Baloch \& HM Aatif, Contributed reagents/ materials/ analysis tools: A Wasaya, Wrote the paper: MF Azhar \& A Aziz.

\section{References}

1. Kadereit G, Borsch T, Weising K \& Freitag H (2003). Phylogeny of Amaranthaceae and Chenopodiaceae and the evolution of $\mathrm{C} 4$ photosynthesis. International $J$ of Plant Sci 164(6): 959-986.

2. Ward SM (1998). A new source of restorable cytoplasmic male sterility in quinoa. Euphytica 101(2): 157-163.

3. Maughan PJ, Bonifacio A, Jellen EN, Stevens MR, Coleman CE, Ricks M \& Fairbanks DJ (2004). A genetic linkage map of quinoa (Chenopodium quinoa) based on AFLP, RAPD, and SSR markers. Theoretical Appl genetics 109(6): 1188-1195.

4. Struwe L (2009). Field identification of the 50 most common plant families in temperate regions (including agricultural, horticultural, and wild species). Rutgers University, New Brunswick, NJ, USA.

5. Cusack DF (1984). Quinua: grain of the Incas. Ecologist 14(1): 21-31.

6. Repo-Carrasco R, Espinoza C, \& Jacobsen SE (2003). Nutritional value and use of the Andean crops quinoa (Chenopodium quinoa) and kañiwa
(Chenopodium pallidicaule). Food Reviews International 19(1-2): 179189.

7. Morales PP \& Curl C (1983). A physicochemical method for total saponin determination in quinoa samples. Rev Bolivia Quim 6: 13-9.

8. Chauhan GS, Zillman RR \& Eskin NM (1992). Dough mixing and breadmaking properties of quinoa wheat flour blends. International $J$ of Food Sci Technol 27(6): 701-705.

9. Linnemann AR \& Dijkstra DS (2002). Toward sustainable production of protein-rich foods: appraisal of eight crops for Western Europe. Part I. Analysis of the primary links of the production chain. Critical Reviews in Food Science and Nutrition 42(4): 377-401.

10. Chauhan GS, Eskin NAM \& Mills PA (1999). Effect of saponin extraction on the nutritional quality of quinoa (Chenopodium quinoa Willd.) proteins. J Food Sci Technology 36(2): 123-126.

11. Ruas PM, Bonifacio A, Ruas CF, Fairbanks DJ \& Andersen WR (1999). Genetic relationship among 19 accessions of six species of Chenopodium L., by Random Amplified Polymorphic DNA fragments (RAPD). Euphytica 105(1): 25-32.

12. Ruales J \& Baboo MN (1992). "Nutritional quality of the protein in quinoa (Chenopodium quinoa, Willd) seeds." Plant Foods for Human Nutrition (Formerly Qualitas Plantarum) 42.1: 1-11.

13. Ruales J, Grijalva YD, LopezJaramillo P \& Nair BM (2002). The nutritional quality of an infant food from quinoa and its effect on the plasma level of insulin-like growth factor-1 (IGF-1) in undernourished children. International Journal of Food Sci Nutrition 53(2): 143-154.

14. Prado FE, Boero C, Gallardo M \& Gonzalez JA (2000). Effect of $\mathrm{NaCl}$ on 
germination, growth, and soluble sugar content in Chenopodium quinoa willd seeds. Botanical Bulletin of Academia Sinica 41.

15. McElhinny E, Peralta E, Mazón N, Danial DL, Thiele $G$ \& Lindhout $P$ (2007). Aspects of participatory plant breeding for quinoa in marginal areas of Ecuador. Euphytica 153(3): 373384.

16. Rodríguez L, Anabalón J \& Isla M (2009). Comparative analysis of genetic and morphologic diversity among quinoa accessions (Chenopodium quinoa Willd.) of the South of Chile and highland accessions. J Plant Breed Crop Sci 1(5):210-216.

17. Bertero HD (2001). Effects of photoperiod, temperature and radiation on the rate of leaf appearance in quinoa (Chenopodium quinoa Willd.) under field conditions. Annals of Botany 87(4): 495-502.

18. Spehar CR \& Rocha JES 2010. Exploiting genotypic variability from low-altitude Brazilian Savannahadapted Chenopodium quinoa. Euphytica (Wageningen) 175: 13-21.

19. Casini P \& La Rocca F (2014). Amaranthuscruentus L. is suitable for cultivation in Central Italy: field evaluation and response to plant densities. Italian $J$ Agronomy 9(4): 166-175.

20. Risic JC \& Galwey NW (1984). The Chenopodium grains of the Andes: Inca crops for modern agriculture, in Advances in Applied Microbiology, ed. by Coaker TH. Academic Press, London, pp. 145-217.

21. Valencia-Chamorro SA (2003). Quinoa, in Encyclopedia of Food Science and Nutrition, ed. by CaballeroB. Academic Press, Amsterdam, pp. 4895-4902.

22. Bhargava A, Shukla S, \& Ohri D (2006). Chenopodium quinoa -an Indian perspective. Industrial Crops and Products 23(1): 73-87.

23. Vega Gálvez A, Miranda M, Vergara J, Uribe E, Puente L \& Martínez EA (2010). Nutrition facts and functional potential of quinoa (Chenopodium quinoa willd.), an ancient Andean grain: a review. J Sci Food Agriculture 90(15): 2541-2547.

24. Thanapornpoonpong SN, Vearaslip S, Pawelzik E \& Gorinstein S (2008). Influence of various nitrogen applications on protein and amino acid profiles of amaranth and quinoa. $J$ Agric Food Chem 56: 11464-11470. 